\title{
Diagnosis and management of optic disc melanocytoma
}

\author{
Diagnóstico e conduta em \\ melanocitoma do disco óptico
}

Marisa Novaes Falleiro Chaves de Figueiredoํ․ Márcia Leite Machado², Fernanda Guedes Oliveira³, Diogo Mafia Vieira³, João Jorge Nassaralla Junior ${ }^{4}$

\begin{abstract}
The optic disc melanocytoma is a benign tumor, with little predisposition to become a melanoma. It is usually asymptomatic, nonetheless should be evaluated periodically, most often by computerized perimetry, which in 9 out of 10 cases will show some alteration. In the following paper we report the case of 61 years old man without previous diagnosis of optic disc melanocytoma and discuss the importance of melanoma differential diagnosis and monitoring.

Keywords: Optic Disc/pathology; Optic nerve tumors/complications; Melanoma/diagnosis; Differential diagnosis; Diagnostic imaging; Case reports

\section{ResUMO}

O melanocitoma do disco óptico é um tumor benigno, com pouca predisposição a transformação maligna para melanoma. Geralmente é assintomático, contudo deve ser avaliado periodicamente com exames, sendo um deles a campimetria computadorizada que se encontra alterada em $90 \%$ dos casos. Relatamos o caso de um homem de 61 anos sem diagnóstico prévio de melanocitoma do disco óptico. Discute-se a importância de um diagnóstico diferencial com melanoma e acompanhamento seriado do paciente.

Descritores: Disco óptico/patologia; Neoplasias do nervo óptico/complicações; Melanoma/diagnóstico; Diagnóstico diferencial; Diagnóstico por imagem; Relatos de casos
\end{abstract}

\footnotetext{
${ }^{1}$ Ophthalmology Resident (R1) of the Instituto de Olhos de Goiânia - Goiânia, GO, Brazil.

2 Ophthalmology Resident (R2) of the Instituto de Olhos de Goiânia - Goiânia, GO, Brazil.

${ }^{3}$ Ophthalmology Resident (R3) of the Instituto de Olhos de Goiânia - Goiânia, GO, Brazil.

${ }^{4}$ Doctorate, Department of Retina and Vitreous of the Instituto de Olhos de Goiânia - Goiânia, GO, Brazil.
}

The authors declare no conflicts of interests.

Received for publication 22/08/2012 - Accepted for publication 13/01/2013 


\section{INTRODUCTION}

$\mathbf{M}$ elanocytoma of the optical disc is a change with which ophthalmologists need to be acquainted, mainly because of the important differential diagnosis with melanoma. It is characterized by a densely pigmented, slightly elevated, and rounded lesion, generally located in the inferior temporal quadrant of the optical disk and typically unilateral. It is considered a benign, asymptomatic tumor evolving with malignant transformation in $1-2 \%$ of cases ${ }^{(1,2)}$.

In general, the melanocytoma is stationary or has a very slow growth. In most cases it does not interfere with visual acuity, and rarely causes a sudden or gradual loss of sight ${ }^{(3,4)}$. The diagnosis is commonly by routine eye examination, and should be supplemented with imaging exams such as ecography, fluorescein angiography and computerized perimetry.

We report the case of a 61-year-old man diagnosed with melanocytoma with normal visual field and no changes in the visual acuity. Exams were performed to elucidate the diagnosis and better conduct.

\section{Case Report}

Male patient, 61 years old, brown, painter, came to the ambulatory of the Eye Institute of Goiânia for a routine ophthalmologic appointment in October 2011. The initial examination revealed better corrected visual acuity of 0.8 in both eyes (BE).

A slit lamp examination of the anterior segment was within the normal range, with all media being transparent and intraocular pressure of $16 \mathrm{mmHg}$ BE. Fundoscopy showed a blackened, rounded and elevated lesion on the papilla of the optic disc, affecting the lower nasal quadrant of the left eye. He had no previous diagnosis of lesions in the eye fundus.

Central computerized perimetry 54/24 (Humphrey 750USA) maintaining regular pattern similar to the contralateral eye (Figure A). Fluorescein angiography TRC 50DX (TopconJapan) showed hypofluorescent papillary lesion at all times and no contrast extravasation (Figure B).

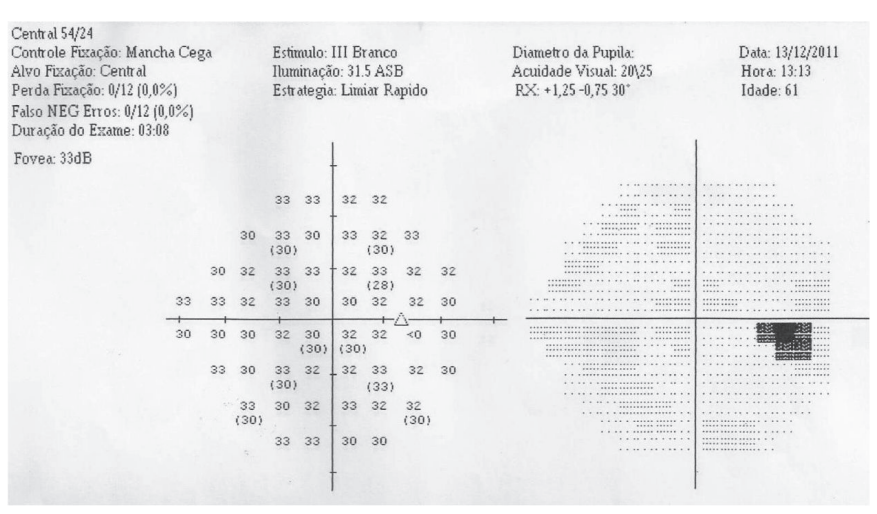

Figure A: Computerized perimetry without increased blind spot.

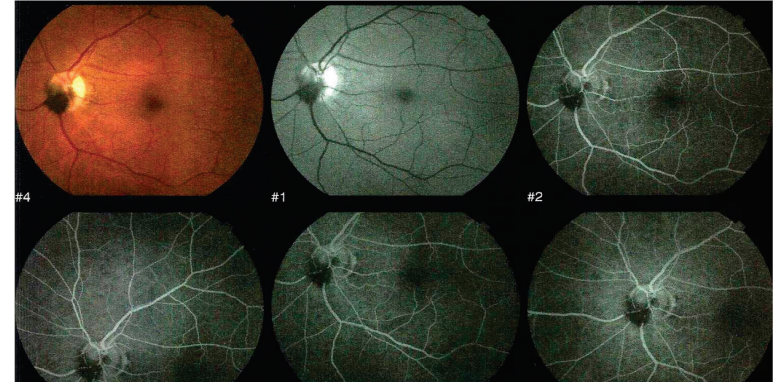

Figure B: Fluorescein angiography showed blockage of fluorescence in the topography of melanocytoma at all times.

Optical coherence tomography (OCT 2000 Topcon-Japan) showed elevated lesion on optical disc with a highly reflective and shading layer through it, without edema in the sensory retina and without infiltration of subretinal fluid in this region (Figure C).

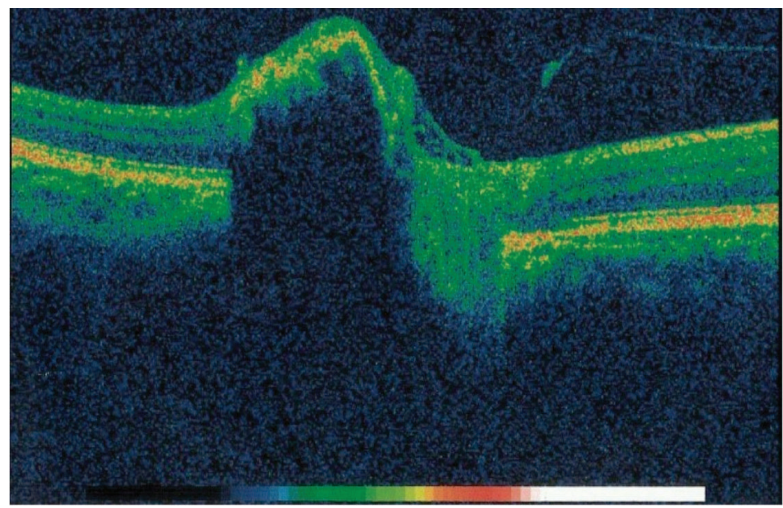

Figure C: OCT showing elevated lesion in the optic nerve location with high reflectivity and shading

The B ecography of the LE showed an elevated, solid lesion with rounded shape in front of the optic nerve of $1.76 \mathrm{~mm}$ in anteroposterior section. And the A ecography showed elevated peaks in the location of the pigmented lesion.

The patient was reassessed with a routine eye exam, fluorescein angiography and OCT two months after diagnosis, with no change in the appearance of the lesion. Currently the patient is in semi-annual follow-up.

\section{Discussion}

The melanocytoma of the optical disc is typically small, of approximately $2 \mathrm{~mm}$ in diameter and $1 \mathrm{~mm}$ in thickness, and most often unilateral. It is a benign rounded tumor, often located in the lower temporal region of the optical disc, and generally stationary. It appears as a pigmented lesion of dark brown or black color. The average age of diagnosis is 50 years, and the distribution is equal among races ${ }^{(1,2)}$.

In the case reported in this study, the tumor had size and shape consistent with what is described in the literature, with $1.76 \mathrm{~mm}$ in the anteroposterior section. However, unlike the statistics it was located in the lower nasal region of the optical disc.

While some melanocytomas are confined at the disk, most cases involve adjacently the retina and choroid. According to Joffe et al. ${ }^{(3)} 18 \%$ of patients present lesion confined to the optic 
nerve head, $77 \%$ extend to the retina, and $47 \%$ have juxtapapillary choroid component. Moreover, it can be associated to optic nerve edema, microhemorrhages, retinal edema or subretinal fluid ${ }^{(5,6)}$.

The melanocytomas of the optic nerve are characterized as stable or show slow growth of the lesion ${ }^{(3)}$. Joffe et al. followed 40 patients for over a year, and found a slight growth in $15 \%$ of cases (3). The growth pattern that can occasionally occur in melanocytomas is still not known. Apple et al. ${ }^{(4)}$ described the first case of malignant transformation of a melanocytoma of the optic nerve. However, there was no evidence regarding the origin of the melanoma which may have arisen from the choroid or the optic nerve.

The differential diagnosis of melanocytoma should be done first with the malignant melanoma due to its morbidity and mortality, so before diagnosing the melanocytoma it is essential to rule out melanoma. Malignant melanoma has as typical characteristics: more than $1.5 \mathrm{~mm}$ of thickness, subretinal fluid, presence of an orange pigment, presence of vascularization in the echography and hyperfluorescence of the lesion in fluorescein angiography ${ }^{(7,8)}$. Other differential diagnoses are: choroidal nevus, hyperplasia of the retinal pigment epithelium, adenoma of the retinal pigment epithelium and metastatic melanoma of the optical disk ${ }^{(9)}$.

Literature describes that a malignant transformation is very rare, approximately $1-2 \%$ of cases ${ }^{(2)}$. It should be considered as a malignant risk if there is progressive growth or extensive involvement of the optic disc with loss of sight, although $10-15 \%$ of melanocytomas have a subtle increase in size during follow-up ${ }^{(4,8)}$.

The close monitoring of the patient is essential in the early months since the identification of a suspicious lesion, with ophthalmologic clinical assessment, besides ecography modes A and $\mathrm{B}, \mathrm{OCT}$, fluorescein angiography and computerized perimetry.

On fluorescein angiography, the melanocytoma shows early hypofluorescence by blocking due to the dense pigmentation of the tumor which remains at all examination times ${ }^{(7,10)}$.

Usually the lesions are asymptomatic; however, it is possible to find defects in the visual field and loss of sight. Over $90 \%$ of cases will have some defect in computerized perimetry, though these defects are rarely symptomatic ${ }^{(11)}$. The changes include increased blind spot and defect in the nerve fiber layer. The case described becomes interesting by the unusual aspect of not showing changes in the visual field.

Most of them do not progress to loss of sight, but in $25 \%$ of cases there may be a slight loss of sight ${ }^{(12)}$. In the case reported there was no loss of sight, which is consistent with the most of cases. The causes of visual loss in melanocytomas of the optic disc are multiple. Joffe et al. ${ }^{(3)}$ assessed 40 patients, and found that in $75 \%$ of eyes the visual acuity ranged from $20 / 15$ to $20 / 30$. Zimmerman ${ }^{(13,14,15)}$ described a case showing ischemic necrosis of a melanocytoma of the optic nerve which was associated to occlusion of the anomalous vascular branch that feeds the tumor and the temporal retina. Despite these isolated reports, the leading cause of decreased vision is attributed to the edema of axons from the compression of the nerve fibers and their vascular supply by the tumor ${ }^{(11)}$.

The ecography is important to monitor the growth of the lesion. The mode A assesses the size of the tumor, and the mode $\mathrm{B}$ discloses in most cases a solid lesion with regular internal reflectivity without internal vascularization ${ }^{(16)}$. The OCT shows no specific changes, but is valuable to monitor the retinal edema and the extension of the subretinal fluid ${ }^{(17)}$.

An unknown and previously undocumented pigmented lesion of the optic disc and peripapillary area is a cause for concern.
However, knowing the main characteristics of a melanocytoma of the optical disc can help diagnosing this lesion and differentiating it from choroidal melanoma. The patient should carry out the above-mentioned exams and return monthly for reassessment. If there is no change in the aspect of lesion, the follow-up becomes semi-annual.

Periodic follow-up is important to assess changes in size, shape and consistency of the lesion. If a melanocytoma of the optical disk has atypical characteristics, we can only rule out melanoma after the patient has been followed up over time and shows no changes suggestive of melanoma.

A large involvement of the optic disc and/or progressive growth of pigmented lesion with loss of vision is suggestive of malignancy ${ }^{(4)}$. In those cases of suspected malignant transformation, one must consider enucleation and brachytherapy.

\section{REFERENCES}

1. Shields JA, Demirci H, Mashayekhi A, Eagle RC Jr, Shields CL. Melanocytoma of optic disc: a review. Surv Ophthalmol. 2006;51(2):93-104.

2. Shields JA, Shields CL, Piccone M, Snady-McCoy LC. Spontaneous appearance of an optic disk melanocytoma in an adult. Am J Ophthalmol. 2002;134(4):614-5.

3. Joffe L, Shields JA, Osher RH, Gass JD. Clinical and follow-up studies of melanocytomas of the optic disc. Ophthalmology. 1979;86(6):1067-83.

4. Apple DJ, Craythorn JM, Reidy JJ, Steinmetz RL, Brady SE, Bohart WA. Malignant transformation of an optic nerve melanocytoma. Can J Ophthalmol. 1984;19(7):320-5.

5. Thomas CI, Purnell EW. Ocular melanocytoma. Am J Ophthalmol. 1969;67(1):79-86.

6. Gouveia EB, Morales MS. Melanocitoma do nervo óptico. Rev Bras Oftalmol. 2008;67(6):321-6.

7. Shields JA, Demirci H, Mashayekhi A, Shields CL. Melanocytoma of optic disc in 115 cases: the 2004 Samuel Johnson Memorial Lecture, part 1. Ophthalmology. 2004;111(9):1739-46.

8. Reese AB. Congenital melanomas. Am J Ophthalmol. 1974;77(6):789-808.

9. Marback RL, Sé DC, Barsante C. Tumores da papila e do nervo óptico. In: Abujamra S, editor. Retina e vítreo: clínica e cirurgia. São Paulo: Roca; 2000. p.387-91.

10. Shields CA, Shields JA. Tumores intra-oculares. In: Vilela MA, editor. Angiografia fluoresceínica: Atlas \& texto. Rio de Janeiro: Cultura Médica; 2005. p.139-40.

11. Osher RH, Shields JA, Layman PR. Pupillary and visual field evaluation in patients with melanocytoma of the optic disc. Arch Ophthalmol. 1979;97(6):1096-9.

12. Saraiva FP, Costa PG, Souza MB, Oyamada MK. Diminuição transitória da acuidade visual associada à melanocitoma. Rev Bras Oftalmol. 2004;63(5/6):321-4.

13. Zimmerman LE, Garron LK. Melanocytoma of the optic disk. Int Ophthalmol Clin. 1962;2:431-4.

14. Zimmerman LE. Melanocytes, melanocytic nevi, and melanocytomas. Invest Ophthalmol. 1965;4:11-41.

15. Zimmerman LE. Changing concepts concerning the malignancy of ocular tumors. Arch Ophthalmol. 1967;78(2):166-73.

16. Byrne SF, Green RL. Intraocular tumors. In: Byrne SF, Green RL, editors. Ultrasound of the eye and orbit. St. Louis: Mosby; 1992. p.180-1.

17. Antcliff RJ, ffytche TJ, Shilling JS, Marshall J. Optical coherence tomography of melanocytoma. Am J Ophthalmol. 2000;130(6):845-7. 